\title{
ESTUDO DA VARIABILIDADE PLUVIOMÉTRICA ESPAÇO-TEMPORAL NA MICRORREGIÃO DE SOUSA, PARAÍBA
}

\section{STUDY OF SPACE-TIME PLUVIOMETRIC VARIABILITY IN THE SOUSA MICRORGION, PARAÍBA}

Maxsuel Bezerra do Nascimento, Gustavo Fernando Santos, Tássio Jordan Rodrigues Dantas da Silva, Linaldo Freire Silva, José Ludemario da Silva Medeiros, Lincoln Eloi de Araújo

Universidade Estadual da Paraíba

maxsuel10gba@hotmail.com, gustavofernandosantos13@gmail.com, tassiojordan@hotmail.com, linaldo.fs@hotmail.com, joseludemariomedeiros@gmail.com, lincolneloi@yahoo.com.br

Submissão: 22 de agosto de 2020 Aceitação: 18 de janeiro de 2021

\section{Resumo}

O Nordeste Brasileiro é uma das regiões mais problemáticas no que se refere à disponibilidade de água, portanto, se tem necessidade de atentar a práticas e métodos para desenvolvimento dessa região, visto que as condições climáticas, a hidrologia e sua vegetação são de extrema importância para compreender como esse ambiente se forma. O objetivo principal deste trabalho é verificar e avaliar a variabilidade climática da microrregião de Sousa, através da análise espaço-temporal mensal e anual da sua precipitação, identificando-se, assim, os períodos secos e chuvosos da área estudada com o auxílio do Índice de Anomalia de Chuva (IAC). Os dados pluviométricos utilizados na pesquisa correspondem às séries mensais de precipitação no período de 1994 a 2017 fornecidos pela AESA, para a avaliação temporal, espacial e para o cálculo do Índice de Anomalia de Chuva (IAC). A microrregião de Sousa apresenta dois períodos distintos, um período de cinco meses chuvosos e outro com sete meses secos. A distribuição espacial da precipitação da microrregião possui áreas bem distintas, onde a maior concentração de precipitação se localiza na parte sudoeste, em contrapartida, a região noroeste e em um ponto na parte central apresentaram valores baixos de precipitação.

Palavras-chave: Períodos Secos, Períodos Chuvosos e Índice de Anomalia de Chuva.

\section{Abstract}

The Brazilian Northeast is one of the most problematic regions in terms of water availability. Therefore, it is necessary to consider the practices and methods for the development of this region, since climatic conditions, hydrology and vegetation are of extreme importance to understand how this environment is formed. The main objective of this work is to verify and evaluate the climatic variability of the Sousa microregion, through the monthly and annual space-time analysis of its precipitation, thus identifying the dry and rainy periods of the studied area with the aid of the Anomaly Index Rainfall (IAC). The rainfall data used in the research correspond to the monthly rainfall series from 1994 to 2017 provided by the EFSA for the temporal and spatial evaluation and for the calculation of the Rainfall Anomaly Index (IAC). The Sousa microregion has two distinct periods, one period of five rainy months and the other with seven dry months. This work has a relevance in the area of ecology, which through the results help to collaborate with the development of the microregion, which through its managers dominate the knowledge of the stations pointed to abundance and water scarcity for the anthropic activities.

Key-words: Dry Periods, Rainy Periods, and Rain Anomaly Index.

\section{INTRODUÇÃO}

O Nordeste Brasileiro é uma das regiões mais problemáticas do país no que se refere à disponibilidade de água. Isto porque a região conta com grande área semiárida, que representa $53 \%$ do território nordestino, onde as chuvas são bastante escassas e irregulares (FERREIRA et al., 2018). Portanto, se tem necessidade de atentar a práticas e métodos para desenvolvimento dessa região, visto que as condições climáticas, a hidrologia e a sua vegetação são de extrema importância para compreender como esse ambiente se forma. 
De acordo com Macedo et al. (2010), o índice de precipitação no estado da Paraíba depende de um conjunto de vários sistemas meteorológicos, tais como: Zona de Convergência Intertropical (ZCIT), Vórtices Ciclônicos de Altos Níveis (VCAN), Sistemas Ondulatórios de Leste, Linhas de Instabilidade, Sistemas Frontais, brisas terrestre e marítima, bandas de nebulosidade, assim como efeitos orográficos locais. Desse modo, esses efeitos locais devem-se às barreiras geográficas, cuja precipitação é menor devido ao Planalto da Borborema que serve de obstáculo, inibindo que as chuvas que vêm do oceano Atlântico cheguem com tanta intensidade nessa região (NASCIMENTO et al., 2019).

Desse modo Francisco et al. (2015) reafirmam que a Paraíba é um dos estados do Nordeste que proporciona uma das maiores variabilidades espaço-temporal das chuvas. A região do Cariri/Curimataú é a parte do estado da Paraíba que menos chove, com precipitações de 300 a $500 \mathrm{~mm}$, enquanto no Sertão e Alto Sertão está em torno de 700 a $900 \mathrm{~mm}$, no Brejo e Agreste, de 700 a $1.200 \mathrm{~mm}$ e o Litoral proporciona as maiores médias anuais de precipitação, alternando entre 1.200 a $1.600 \mathrm{~mm}$.

Considerando essa precipitação temporal irregular, faz-se necessário o monitoramento por meio do emprego de índices climáticos, os quais permitem desenvolver um sistema de acompanhamento dos períodos secos e chuvosos, com informações anuais, sazonais ou mensais (DA SILVA, 2009), o que auxilia a entender como as precipitações de determinada região, estado ou município se constituem.

De acordo com Costa e Silva (2017), o monitoramento desses eventos de precipitação pluviométrica pode ser realizado através da utilização de índices de verificação climática, os quais caracterizam os períodos secos e chuvosos, para entender o comportamento climatológico de uma localidade, estado ou região. Em função disso, 0 monitoramento constante dos Índices de Seca e a aplicação do sistema de classificação de secas anuais podem se constituir em uma ferramenta-chave para 0 planejamento e gestão dos recursos hídricos em uma localidade.

Neste sentido, a escolha da Microrregião de Sousa se dá pelo fato de a mesma estar inserida em um polígono de secas no Nordeste brasileiro (NEB), devido às suas características físicas. Assim sendo, se verifica a necessidade de investigar os fatores da variabilidade pluviométrica para entender o comportamento da região, e compreender se ocorrem impactos significativos no decorrer dos anos.

Diante disso, o objetivo principal deste trabalho é verificar e avaliar a variabilidade da pluviométrica na microrregião de Sousa, através da análise espaço-temporal mensal e anual da sua precipitação, identificando-se, assim, os períodos secos e chuvosos da área estudada com o auxílio do Índice de Anomalia de Chuva (IAC).

\section{MATERIAL E MÉTODOS}

\subsection{Caracterização da Área de Estudo}

O presente trabalho tem como área de estudo a microrregião de Sousa (Figura 1), que pertence à mesorregião do Sertão Paraibano, localizado no Estado da Paraíba. Essa região possui uma área total de $4.784,729 \mathrm{~km}^{2}$, com população estimada, em 2017 pelo IBGE (2017), em 176.859 habitantes residentes em dezessete municípios, sendo eles: Aparecida (8.430 hab.), Cajazeirinhas (3.197), Condado (6.753), Lastro (2.725), Malta (5.665), Marizópolis (6.614), Nazarezinho (7.296), Paulista (12.308), Pombal (32.766), Santa Cruz (6.585), São Bentinho (4.540), São Domingos (3.120), São Francisco (3.363), São José da Lagoa Tapada (7.679), Sousa (69.554), Vieirópolis (5.358) e Vista Serra (3.808).

A microrregião de Sousa se localiza dentro da Bacia Hidrográfica do Rio Piranhas, possuindo grande quantidade de reservatórios que abastecem a população local, para as diversas atividades econômicas.

De acordo com Barbosa (2017), as atividades econômicas encontradas nos municípios da Microrregião de Sousa estão no setor agropecuário, destacando-se os municípios de Sousa, Pombal, Paulista e Aparecida, enquanto os setores industrial e de serviços estão concentrados em Sousa.

O clima da microrregião de Sousa, que está inserido no Sertão, é o Aw marcante, ou seja, clima de savana segundo a classificação de Köppen-Geiger, cujas principais características relacionam-se às elevadas temperaturas e às chuvas de verão e outono, (semiúmido) (FRANCISCO, 2010). 
Figura 1. Microrregião de Sousa, Paraíba
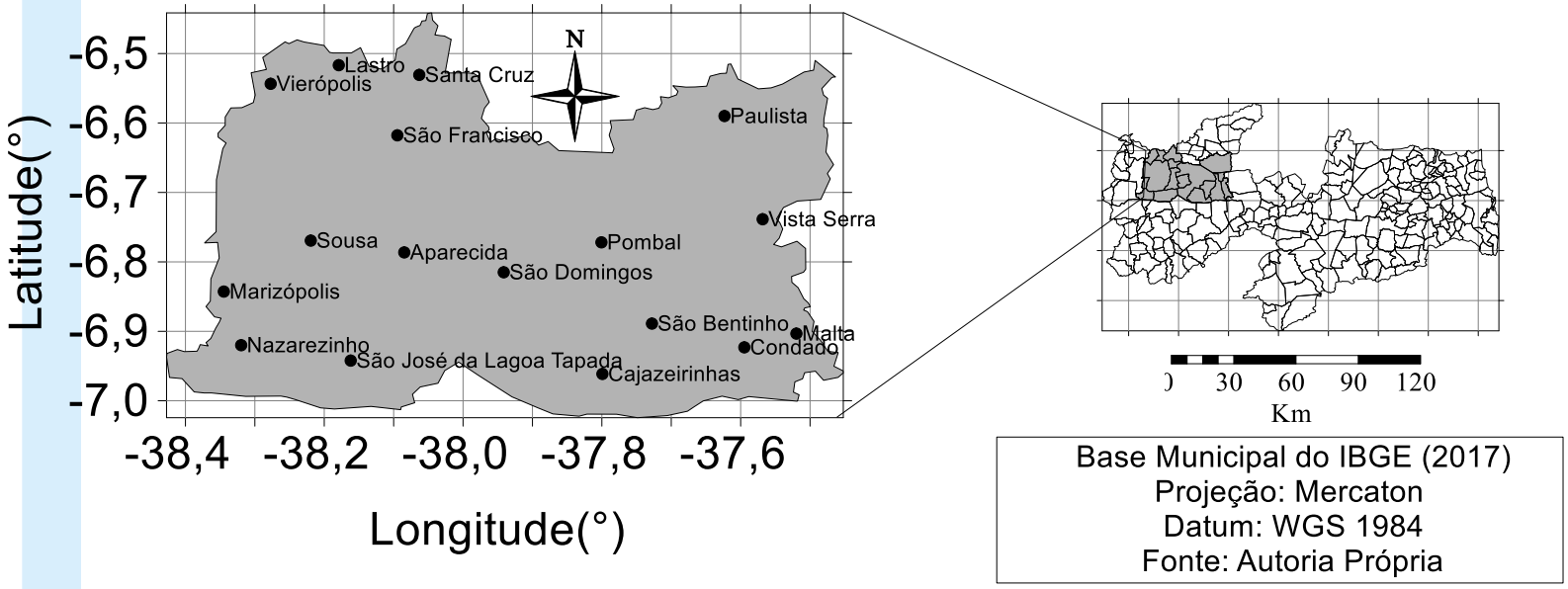

Fonte: Elaborada pelos autores.

Figura 2. Estações pluviométricas localizadas na microrregião de Sousa consideradas para avaliação espaço-temporal

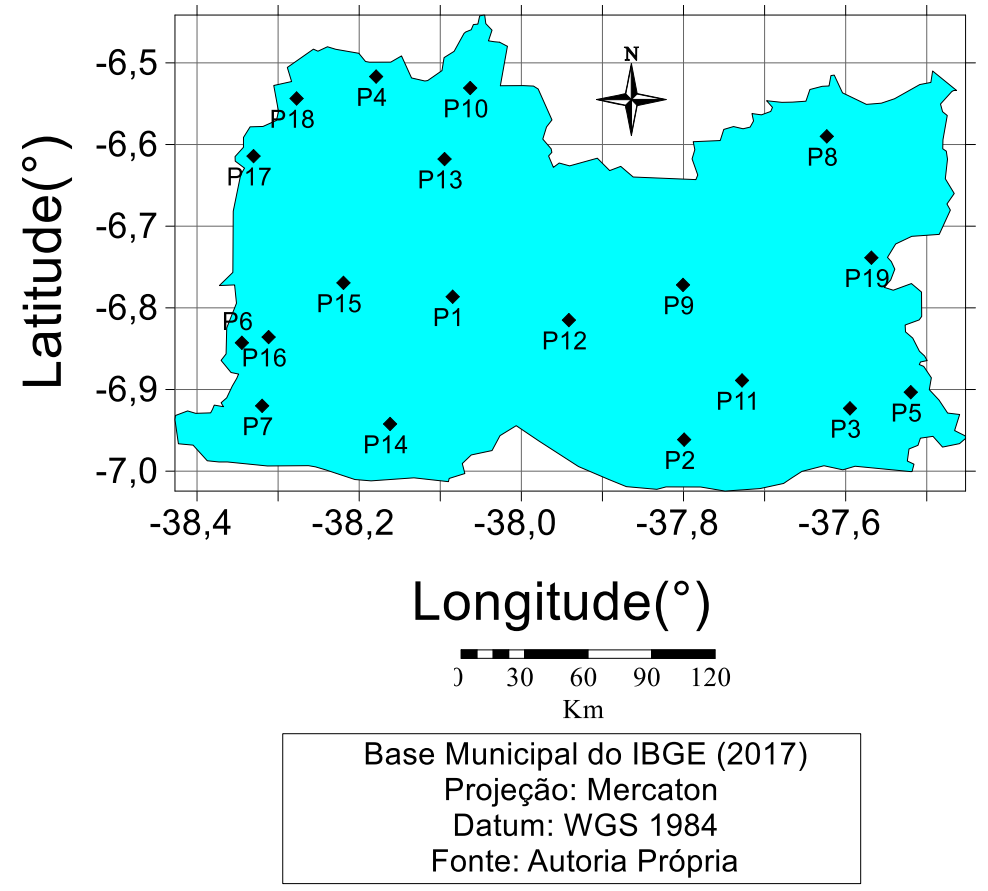

Fonte: Elaborada pelos autores.

Por meio desses valores, foi possível apurar a média mensal de longa duração, ou seja, a precipitação média mensal de longa duração, calculada da seguinte maneira, por exemplo, para o mês de janeiro: (JanAno1 + JanAno2 + ...+ JanAno24) / soma da precipitação em todos os meses de Janeiro. Do mesmo modo, calculou-se a média mensal para todos os meses. Em seguida, criou-se uma planilha com a média acumulada e mensal de cada estação da sua média histórica de 24 anos, para poder fazer a interpolação dos dados, onde foram plotados no software Surfer 8.0 através do método de Krigagem ordinária, a fim de gerar a figura de espacialização da microrregião de Sousa.

Deste modo, ao longo da série histórica dos dados, foram encontradas algumas lacunas, porém, elas não representaram alterações significativas nos resultados. De acordo com Nikolova (2007), tais lacunas não devem ser preenchidas, pois a reposição de valores em falta na série histórica de precipitação ocasiona mais 
subjetividade à investigação.

Para análise da hipsometria (relevo) e da declividade, foram utilizadas imagens SRTM (Shuttle Radar Topography Mission) com resolução espacial de 30 metros, disponibilizadas gratuitamente pelo site TOPODATA (http://www.webmapit.com.br/inpe/topodata/), no qual contém os dados morfométricos do Brasil, sendo as cartas utilizadas as 06\$39 e 07S39. Os referidos mapas foram analisados e espacializados por meio do software livre QGIS 2.18.

O mapa hipsométrico foi confeccionado com base no Modelo Digital do Terreno (MDT) e dividido em 10 classes altimétricas, segundo o método de "quebras naturais" (natural breaks), no qual a distribuição do conjunto de classes maximiza a diferença entre as classes e identifica os pontos de quebra que melhor agrupem valores similares.

Através das imagens SRTM que consistem em matrizes com dados de elevação (MDT), utilizaram-se as ferramentas de geoprocessamento, para obter o mapa de declividade. Assim sendo, foram estabelecidas seis classes de declividade descritas na Tabela 1 (EMBRAPA, 1979), em que uma rampa de cores varia entre o verde, para o menor declive, e vermelho, para o maior valor de declividade, facilitando, assim, a interpretação dos dados gerados.

Tabela 1. Classes de declividade em valores percentuais

\begin{tabular}{cc}
\hline Declividade (\%) & Classes \\
\hline $0-3$ & Plano \\
$3-8$ & Suave ondulado \\
$8-20$ & Ondulado \\
$20-45$ & Fortemente ondulado \\
$45-75$ & Montanhoso \\
$>75$ & Relevo escarpado \\
\hline
\end{tabular}

Fonte: EMBRAPA (1979).

Será usado o IAC anual desenvolvido e utilizado por Rooy (1965) e adaptado por Freitas (2005); os mesmos foram usados para eventos mensais e anuais, obtido a partir das equações:

$I A C=3\left[\frac{(N-\bar{N})}{(\bar{M}-\bar{N})}\right]$

Para anomalias positivas

$I A C=-3\left[\frac{(N-\bar{N})}{(\bar{X}-\bar{N})}\right]$

Para anomalias negativas

Sendo:

$\mathrm{N}=$ Evento em análise

$\bar{N}$ = precipitação média mensal de longa duração da série histórica $(\mathrm{mm})$;

$\bar{M}=$ média dos dez maiores eventos de precipitações mensais da série histórica $(\mathrm{mm})$;

$\bar{X}=$ média dos dez menores eventos de precipitações mensais da série histórica $(\mathrm{mm})$

Utilizaram-se 19 (dezenove) postos pluviométricos, distribuídos nos municípios da microrregião de Sousa, segundo uma série histórica de 24 anos, sendo esses dados coletados e alocados em planilhas eletrônicas no software Excel, permitindo realizar os cálculos atribuídos aos postos analisados de forma individual, ou seja, um a um, e posteriormente, após tirar a média de cada um dos 19 pluviômetros, foram realocados para uma planilha geral, ou seja, os 19 postos já com a média histórica dos 24 anos, e assim verificar o IAC através dos cálculos demonstrados na equação 1 e 2.

Sob o ponto de vista climatológico, estas séries são consideradas curtas, no entanto, de acordo com Dos Santos et al., (2011), nos permitem formular hipóteses sobre tendências de aumento ou redução das chuvas em condições atmosféricas extremas. Conforme os mesmos autores, é recomendada uma série histórica de 30 anos de dados para se aplicar o IAC, porém, caso a série tenha tempo inferior a 30 , indica-se uma adaptação, de forma que a quantidade de médias utilizadas para se calcular o IAC seja modificada proporcionalmente à quantidade de dados disponíveis. Deve-se, assim, calcular uma série de dados de 24 anos, obtendo as médias das 8 maiores e as 8 menores precipitações 
totais do período analisado. Depois de efetivado o cálculo do IAC, os valores gerados serão classificados de acordo com sua intensidade (Tabela 2).

Os resultados foram analisados $e$ classificados de acordo com a metodologia adaptada por Freitas (2005) e readaptada por Araújo et al., (2009), utilizando uma nova classificação de anos secos e úmidos.
Para compreender melhor a distribuição da precipitação entre os períodos secos e chuvosos na microrregião de Sousa, foram analisados anos específicos da série histórica $e$ selecionados 2 anos secos e 2 anos úmidos. A escolha desses anos se deve ao fato de que foram anos extremos (extremamente secos e úmidos) com relação aos demais anos da série histórica.

Tabela 2. Classes de Índice de Anomalia de Chuva (IAC) da microrregião de Sousa

\begin{tabular}{ccc}
\hline & FAIXA DO IAC & CLASSES \\
\hline & Acima de 4 & Extremamente úmido \\
\hline Índice & $2 \mathrm{a} 4$ & Muito úmido \\
\hline De anomalia & $0 \mathrm{a} 2$ & Úmido \\
\hline De chuva & 0 a -2 & Seco \\
\hline (IAC) & -2 a -4 & Muito seco \\
\hline & Abaixo de -4 & Extremamente seco \\
\hline
\end{tabular}

Fonte: Araújo et al. (2009).

\section{RESULTADOS E DISCUSSÃO}

A microrregião de Sousa apresenta dois períodos distintos, um período de cinco meses chuvosos e outro de sete meses secos. O período chuvoso ocorre entre os meses de janeiro a maio, sendo o mês de março a maior lâmina precipitada média, em que atinge o valor de 190,8 mm. Em contrapartida, o período seco ocorre entre os meses de junho a dezembro, sendo setembro o mês que se destaca como o mais seco, com média de 1,6 mm de precipitação (Figura 3).

\section{Figura 3. Precipitação média mensal de longa duração da microrregião de Sousa}

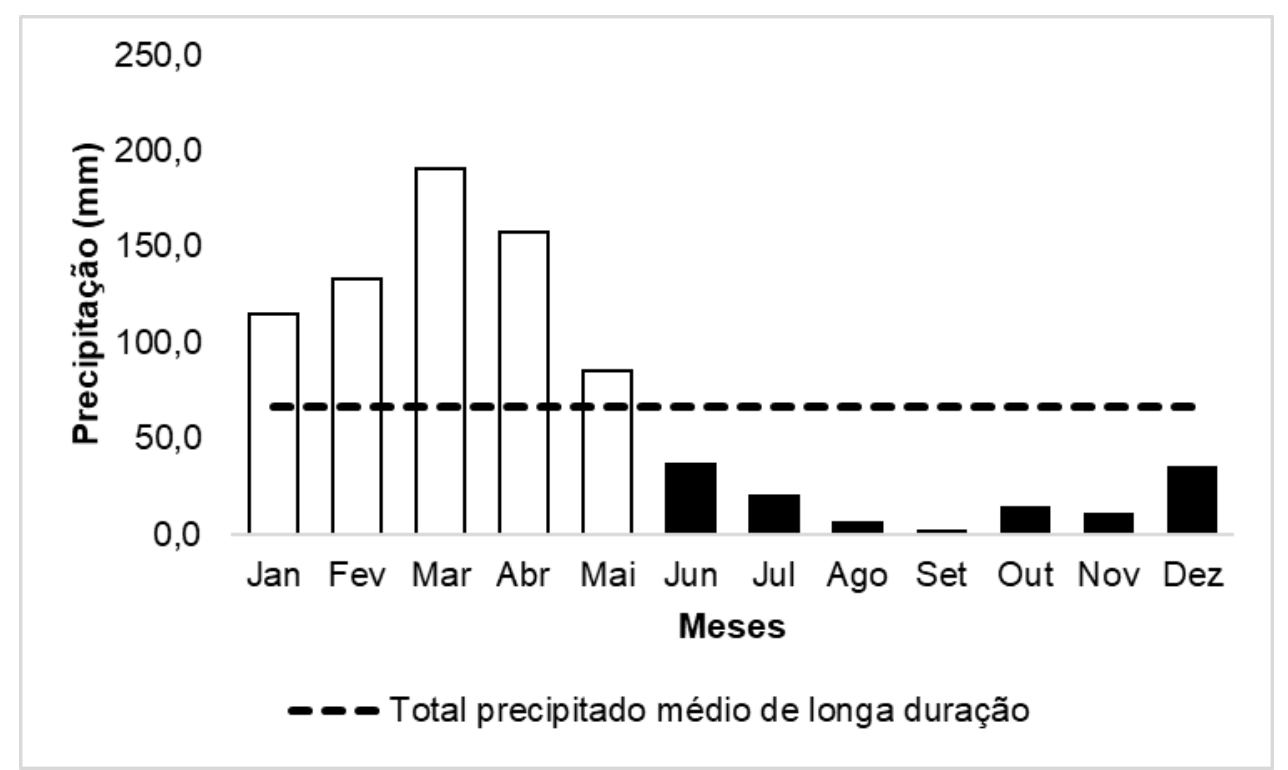

Fonte: Elaborada pelos autores.

A distribuição da precipitação média da microrregião de Sousa é apresentada na Figura 4, na qual se vê que $85 \%$ da precipitação ocorre no período chuvoso. Esse fato é de grande importância, pois é a partir do conhecimento de tais dados que se pode elaborar e prospectar ações futuras para o desenvolvimento da região. Cabe destacar que esse grande acúmulo da precipitação se dá nos cinco (5) primeiros meses do ano. Silva et al., (2012) salientam que o conhecimento da variabilidade inter e intra-anual da precipitação é bastante útil para vários 
propósitos, inclusive na formulação de táticas para implantações de culturas.

Por outro lado, $15 \%$ do total precipitado na microrregião acontecem no período seco, o que nos leva a constatar que é necessário planejamento apropriado durante esses sete (7) meses por parte dos gestores municipais, a fim de criarem métodos de controle dos reservatórios locais. Da mesma forma, os agricultores devem buscar alternativas em suas propriedades, a exemplo das cisternas, e a população se previr abastecendo e estocando a água para que não ocorra racionamento durante esses meses.

\section{Figura 4. Percentual da precipitação da microrregião de Sousa nas estações seca e chuvosa}

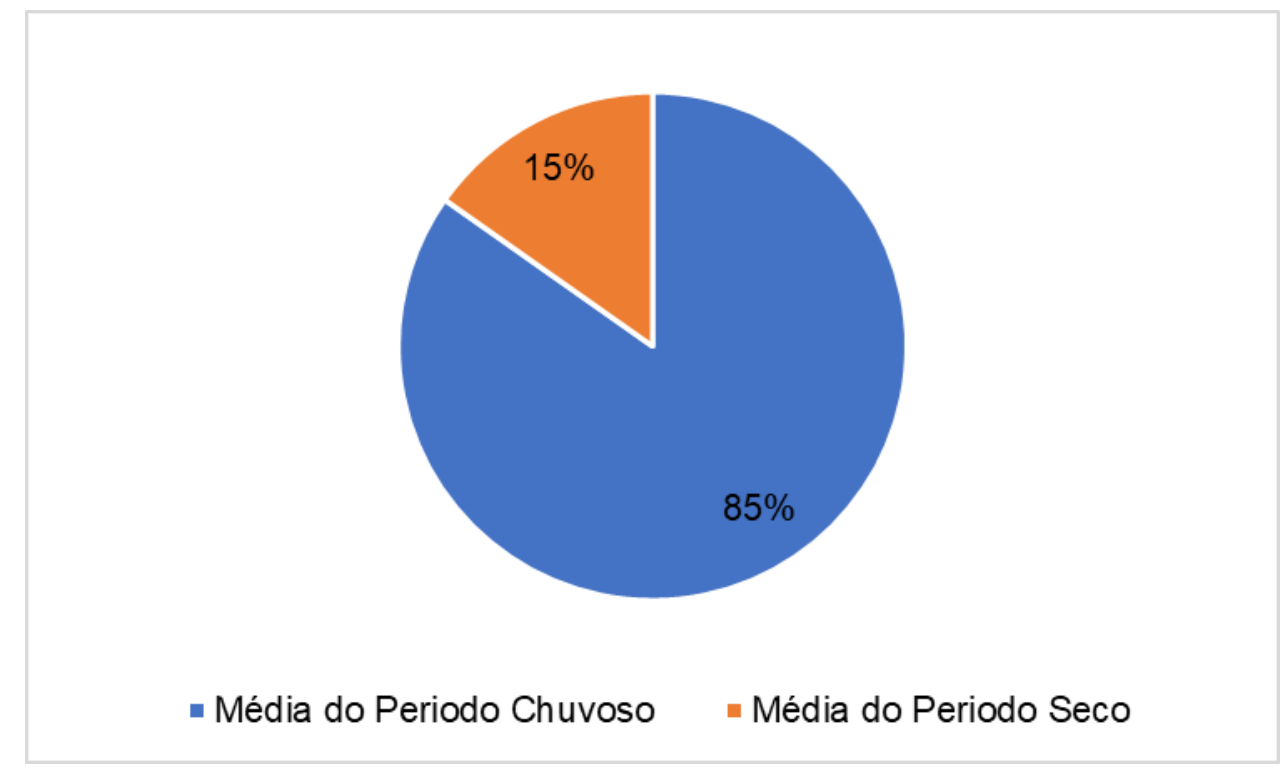

Fonte: Elaborada pelos autores.

Por meio das séries históricas das estações consideradas, foi realizada a espacialização da precipitação total anual de longa duração na Microrregião de Sousa (Figura 5). Verificou-se que os maiores valores de precipitação ocorrem no sudoeste, com valores variando de 880 a 940 $\mathrm{mm}$, É notório que ao longo da microrregião a precipitação diminui em certos locais, o que pode estar relacionado diretamente com o relevo do local analisado. Os menores valores se encontram na parte central, em torno de $700 \mathrm{~mm}$, e, principalmente, a noroeste, com $600 \mathrm{~mm}$, sendo esta a área com menos abundância de chuvas.

Assim, essa distribuição na precipitação (Figura 5) ajuda a compreender de que maneira as chuvas se comportam ao longo da microrregião de Sousa e os benefícios desses dados, os quais servem de subsídio para que cada município possa se planejar, visto que a microrregião representa diferentes níveis de pluviosidade na sua espacialização, impactando não só nas atividades humanas, como também na fauna e flora.

Para a análise da Hipsometria (Figura 6) da microrregião de Sousa, observa-se que a área possui altitudes que variam de 173 a $482 \mathrm{~m}$, cujas áreas mais baixas se encontram a Nordeste e em alguns pontos da parte central, em torno de 173 a 207 metros, enquanto as áreas mais elevadas estão a Norte, Noroeste, Sudoeste e Sudeste e em alguns pontos na parte central, com variações de 413 a $448 \mathrm{~m}$. Notou-se que a elevação de boa parte da área estudada fica entre 242 a 276 metros.

Comparando-se a precipitação acumulada da microrregião (Figura 6) com o mapa hipsométrico (Figura 6), notou-se que a pressão do sotavento no relevo influencia em certos pontos da área noroeste, onde apresentou um menor índice de chuvas orográficas, significando, assim, uma área mais seca. Por outro lado, o relevo não interferiu em certos pontos, como na parte central e na área sudeste. Destaca-se, ainda, que o relevo não influenciou a área sudoeste, mesmo tendo bastante altitude, apresentando-se como o local de maior precipitação. E, por fim, verificou-se que, nas demais áreas onde o relevo variou de 242 a 276 metros, a precipitação ficou entre 780 a $820 \mathrm{~mm}$ através do barlavento. 
Figura 5. Precipitação total anual de longa duração na microrregião de Sousa

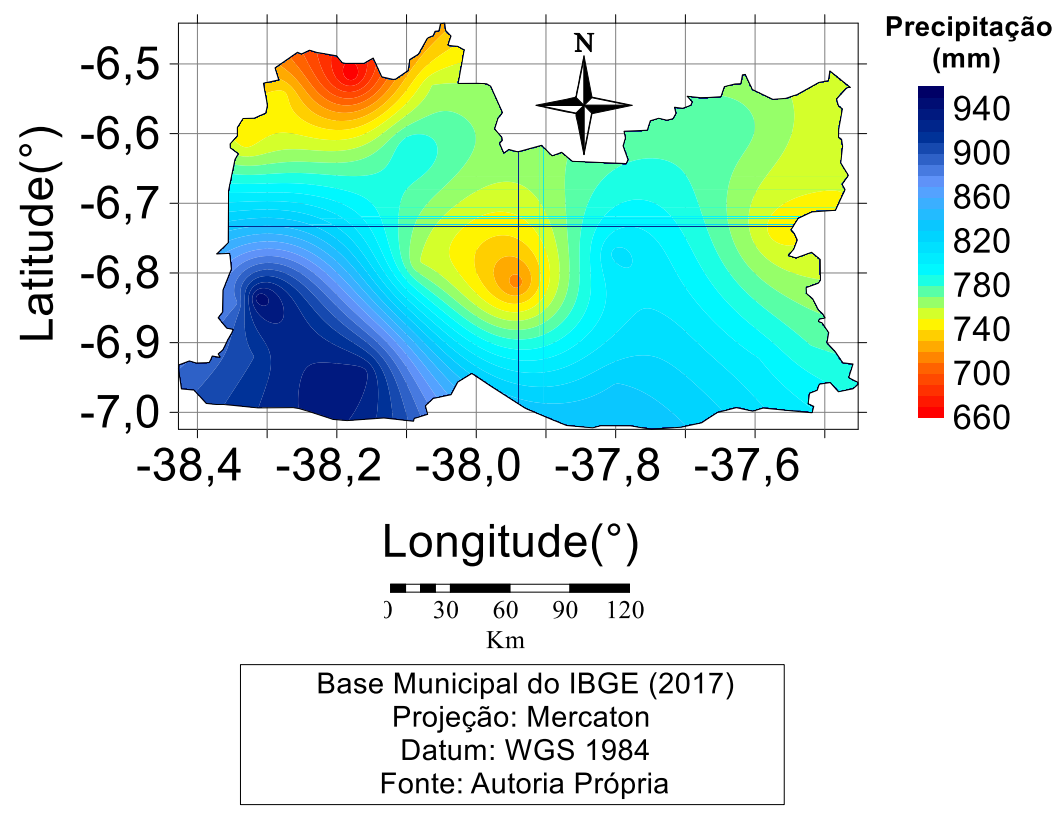

Fonte: Elaborada pelos autores.

Figura 6. Hipsometria da microrregião de Sousa

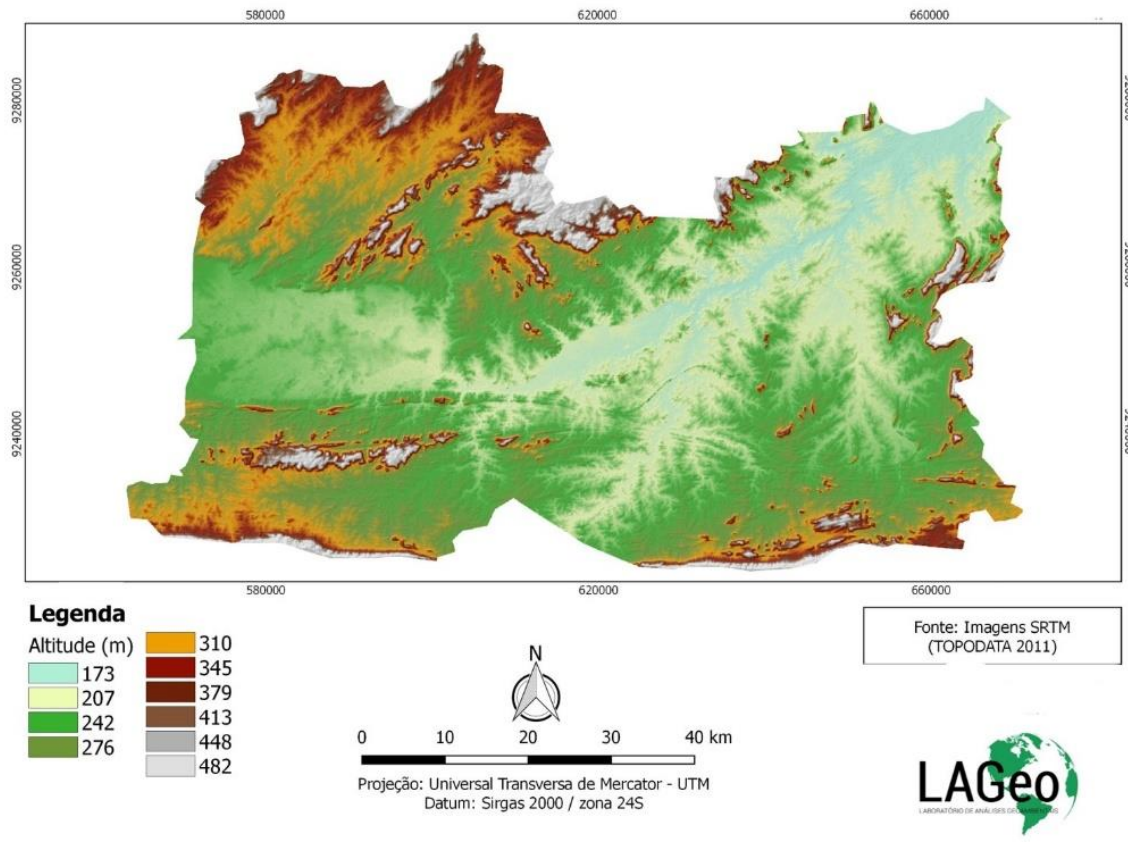

Fonte: Elaborada pelos autores.

A declividade da Microrregião de Sousa (Figura 8) demonstra as inclinações da área em relação a um eixo horizontal e se caracteriza, predominantemente, como plano e suave ondulado, de acordo com a classificação da
Embrapa (1979). As áreas de maior declividade são representadas pela classe 'montanhoso', ocorrendo nas vertentes das principais serras e depressões sertanejas da região. 
Figura 7. Declividade da microrregião de Sousa

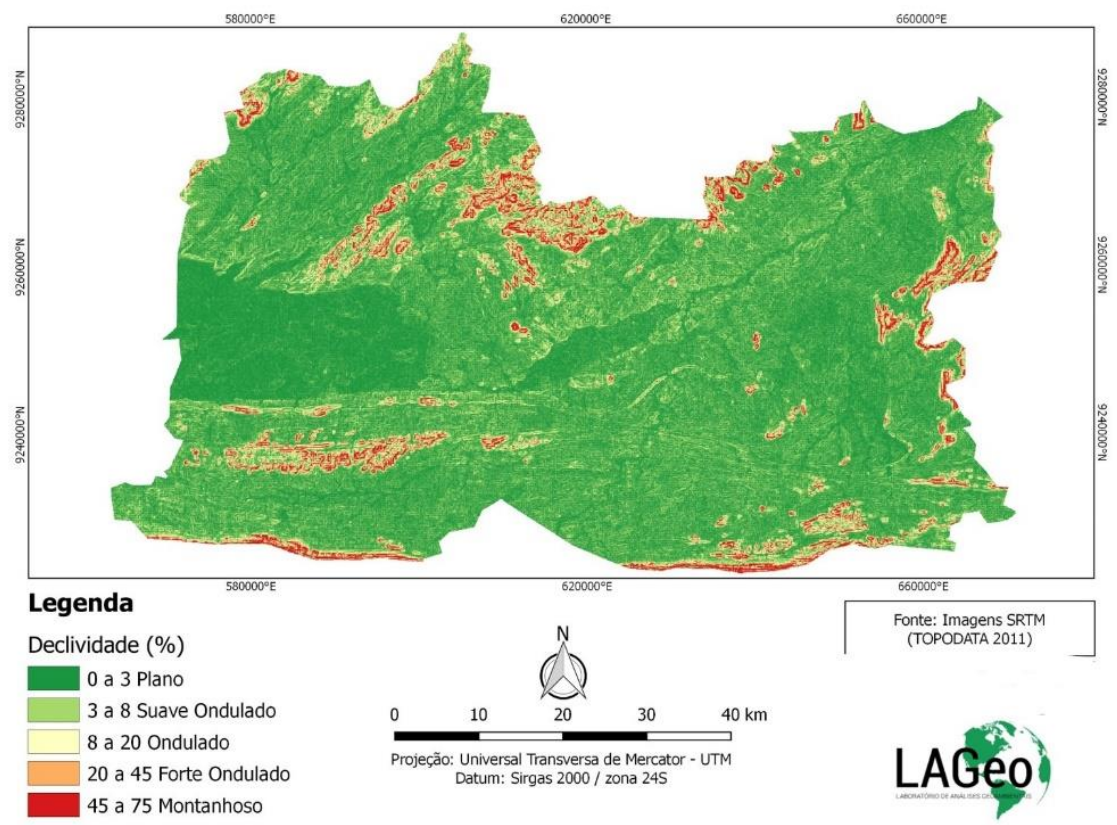

Fonte: Elaborada pelos autores.

Com a finalidade de melhor compreender o comportamento dinâmico da precipitação, analisou-se a espacialização da microrregião de Sousa mensalmente (Figura $8 \mathrm{~A}$ a L). Apresentase o comportamento da precipitação de janeiro a dezembro, sendo o mês de janeiro (Figura 8 A) o início do período chuvoso, cujos maiores índices ocorrem na área sul, atingindo $172 \mathrm{~mm}$, e os menores na área norte, mais precisamente a noroeste da microrregião, com cerca de $75,5 \mathrm{~mm}$. Para o mês de fevereiro (Figura $8 \mathrm{~B}$ ), destaca-se que em todos os municípios a precipitação encontra-se acima de $110 \mathrm{~mm}$, sendo que o seu maior valor foi localizado no sudoeste, atingindo $173 \mathrm{~mm}$.

Março (Figura $8 \mathrm{C}$ ) é um mês de extrema importância para toda a microrregião, pois é o mais representativo em termos de precipitação, de 153 a $239 \mathrm{~mm}$, necessitando por parte dos gestores desses municípios a implementação de alguns métodos para 0 aproveitamento deste recurso natural. A utilização da cisterna é uma política pública de abastecimento de água bastante comum, já que a captação de água de chuva é uma técnica de baixo custo e adaptável à simplicidade do povo do Sertão (SARMENTO et al., 2017).

Já no mês de abril (Figura $8 \mathrm{D}$ ), em toda microrregião, observa-se que a precipitação ficou em torno de $117 \mathrm{~mm}$, e o local de maior lâmina precipitada foi a parte sul central com valores de
$190 \mathrm{~mm}$. Maio (Figura $8 \mathrm{E}$ ), último mês do período chuvoso e de transição para o período seco da microrregião estudada, apresentou valores entre 68,5 a $107,5 \mathrm{~mm}$, evidenciando que as áreas central-sul e noroeste foram as de menor precipitação, enquanto a nordeste e a oeste, as de maior pluviosidade.

Destaca-se, assim, que, nos cinco primeiros meses, a produtividade nesses municípios cresce, com as culturas de soja, cana-de-açúcar, milho, café, mandioca, arroz, laranja, feijão, algodão, banana, fumo, batata inglesa, tomate, trigo, uva, cebola, cacau, amendoim e pimenta do reino.

No mês de junho (Figura $8 \mathrm{~F}$ ), início do período seco da microrregião, observou-se diminuição considerável da precipitação ao longo dos municípios. Foi possível evidenciar que os maiores valores foram localizados em pequenas áreas na parte central, com cerca de $44,8 \mathrm{~mm}$, e os menores, na área leste e noroeste, com 24,4 $\mathrm{mm}$. Já para o mês de julho (Figura $8 \mathrm{G}$ ), os maiores índices foram localizados em pequenos pontos na área mais ao noroeste, com $34,8 \mathrm{~mm}$ de precipitação, e os seus menores valores em pequenos pontos no sudoeste e noroeste, com 11 $\mathrm{mm}$.

Porém, nos meses de agosto (Figura $8 \mathrm{H}$ ) e setembro (Figura 8 I), a precipitação diminuiu gradativamente em todo município, sendo os dois meses com menor intensidade de chuvas da 
microrregião de Sousa, cujos valores máximos encontrados não passaram de $9 \mathrm{~mm}$, e algumas áreas chegando a 0 . Assim sendo, é de extrema importância que nesses meses os gestores municipais, junto com os proprietários locais e toda população fiquem atentos à questão da água, adotando uso consciente e adequado ao equilíbrio ambiental.

Em outubro (Figura $8 \mathrm{~J}$ ) e novembro (Figura $8 \mathrm{~K}$ ), a precipitação aumenta, variando em torno de $3 \mathrm{~mm}$ a 20,7 mm, respectivamente. Já dezembro (Figura 8 L) proporciona um amplo aumento da precipitação, se comparado aos meses anteriores, tendo em vista que esse mês é o de transição do período seco para o chuvoso. Notou-se que os maiores valores foram observados na parte oeste, com $50,9 \mathrm{~mm}$, e os menores, em certo ponto da parte central da microrregião, não passando de $15 \mathrm{~mm}$.

Figura 8. Médias mensais da microrregião de Sousa-PB: janeiro $(A)$, fevereiro $(B)$, março $(C)$, abril $(D)$, maio $(E)$, junho $(F)$, julho $(G)$, agosto $(H)$, setembro $(I)$, outubro $(J)$, novembro $(K)$, dezembro $(L)$.
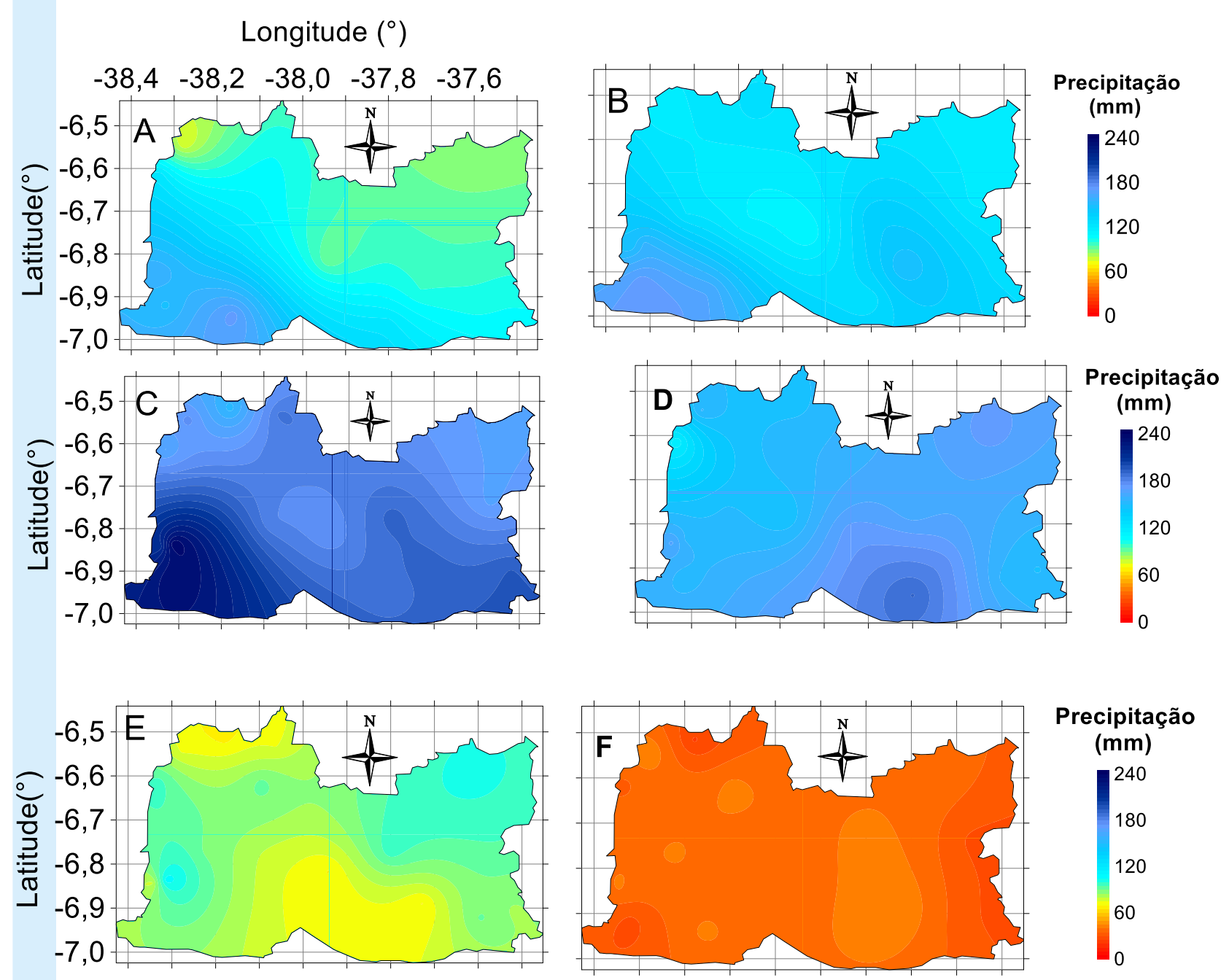

Precipitação
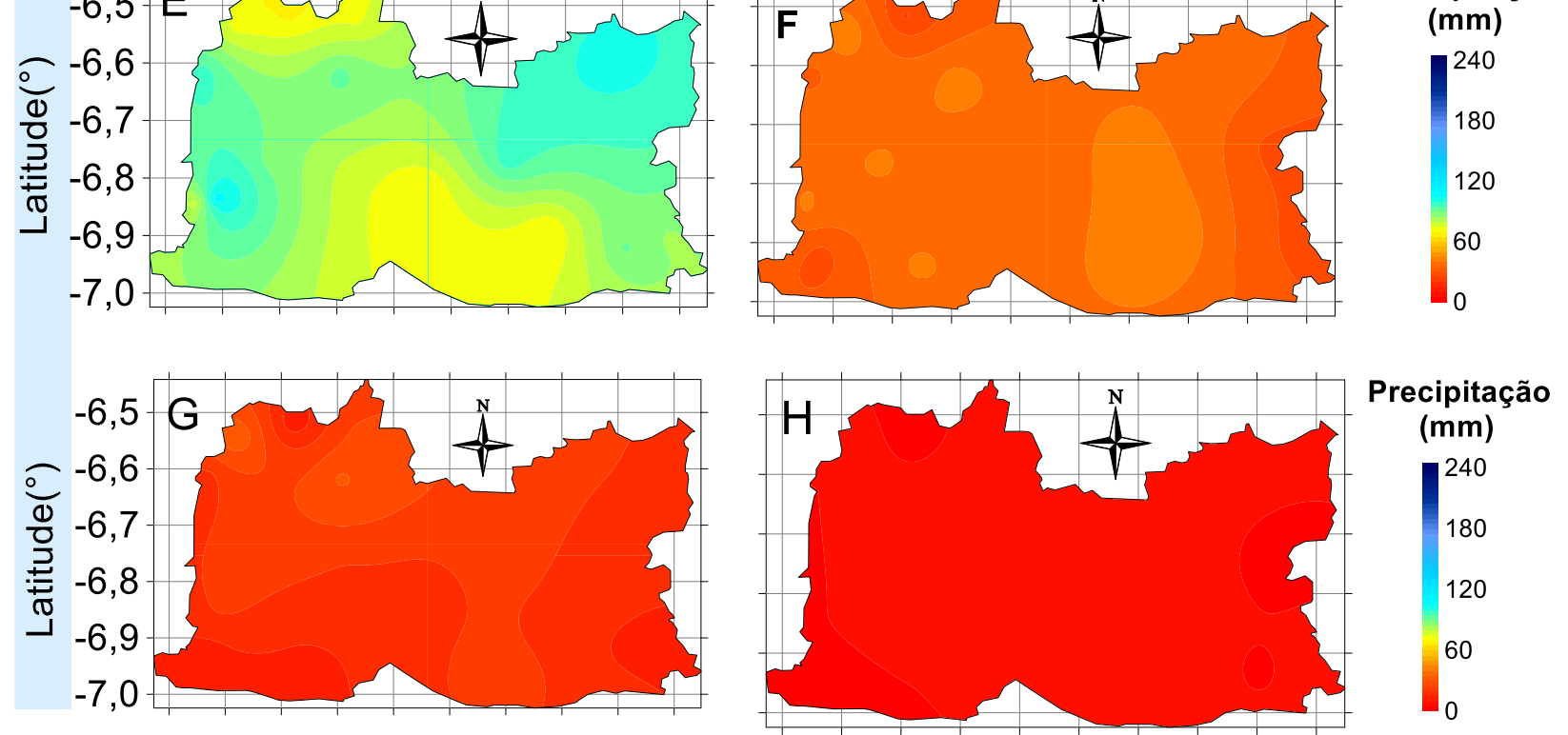

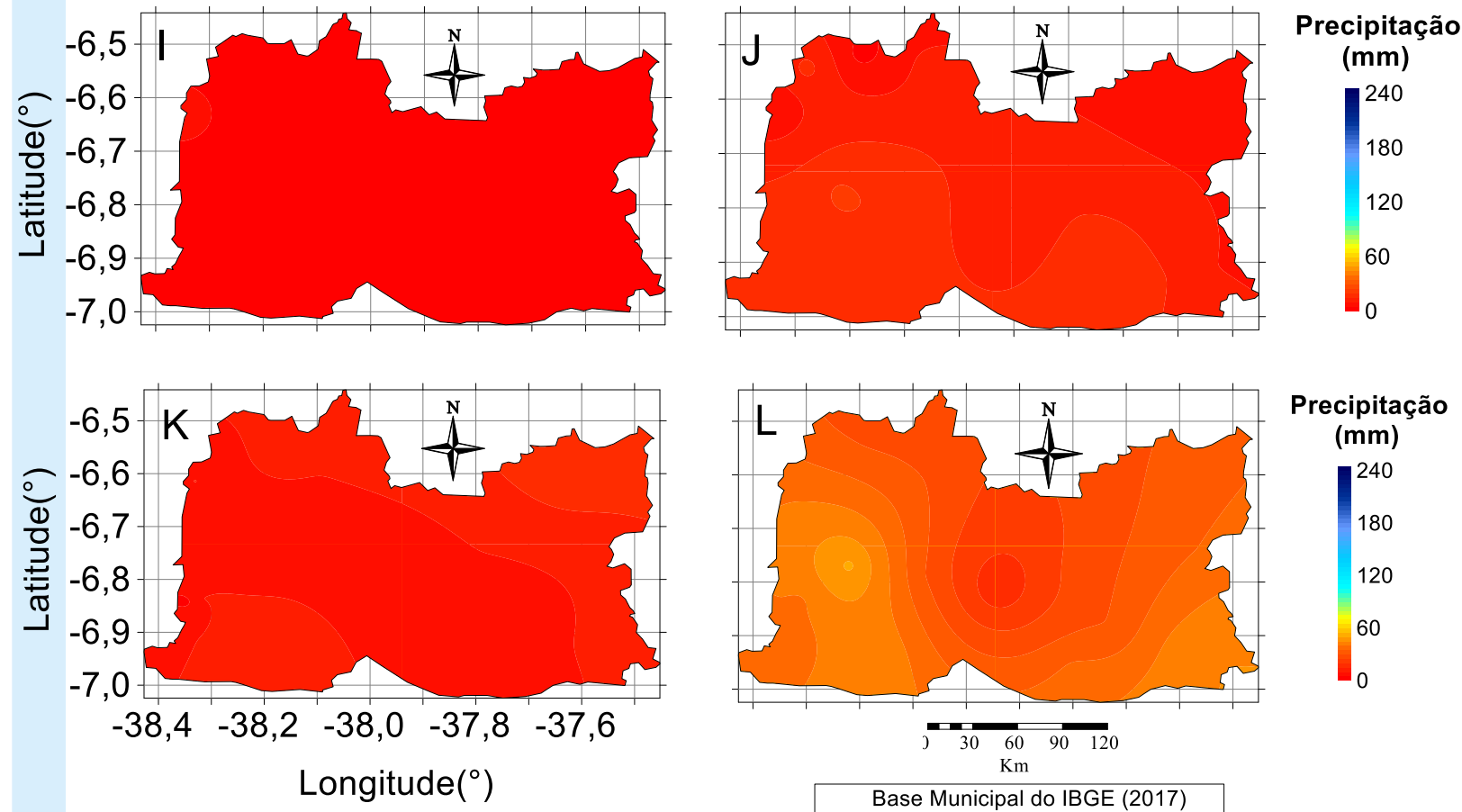

Fonte: Elaborada pelos autores.

Para melhor avaliar a variabilidade da precipitação, aplicou-se o Índice de Anomalia de Chuva (IAC), o qual avalia o grau de severidade dos eventos e de duração de períodos secos e úmidos da série histórica de precipitação. De acordo com a Figura 9, a série é composta por onze anos chuvosos, classificados de acordo com a Tabela 2, entre ÚMIDO (1995, 1996, 1999,

2000, 2002 e 2006), MUITO ÚMIDO (1994, 2004 e 2006) e EXTREMAMENTE ÚMIDO (2008 e 2009). Ainda conforme a mesma tabela, foram encontrados doze anos secos, classificados como SECO (1997, 2003, 2007, 2013, 2014 e 2016), MUITO SECO (2001, 2005, 2015 e 2017) e EXTREMAMENTE SECO (1998 e 2012). Já o ano de 2010 ficou estável, com o seu IAC em 0.

Figura 9. Índice de Anomalia de Chuva (IAC) da Microrregião de Sousa-PB.

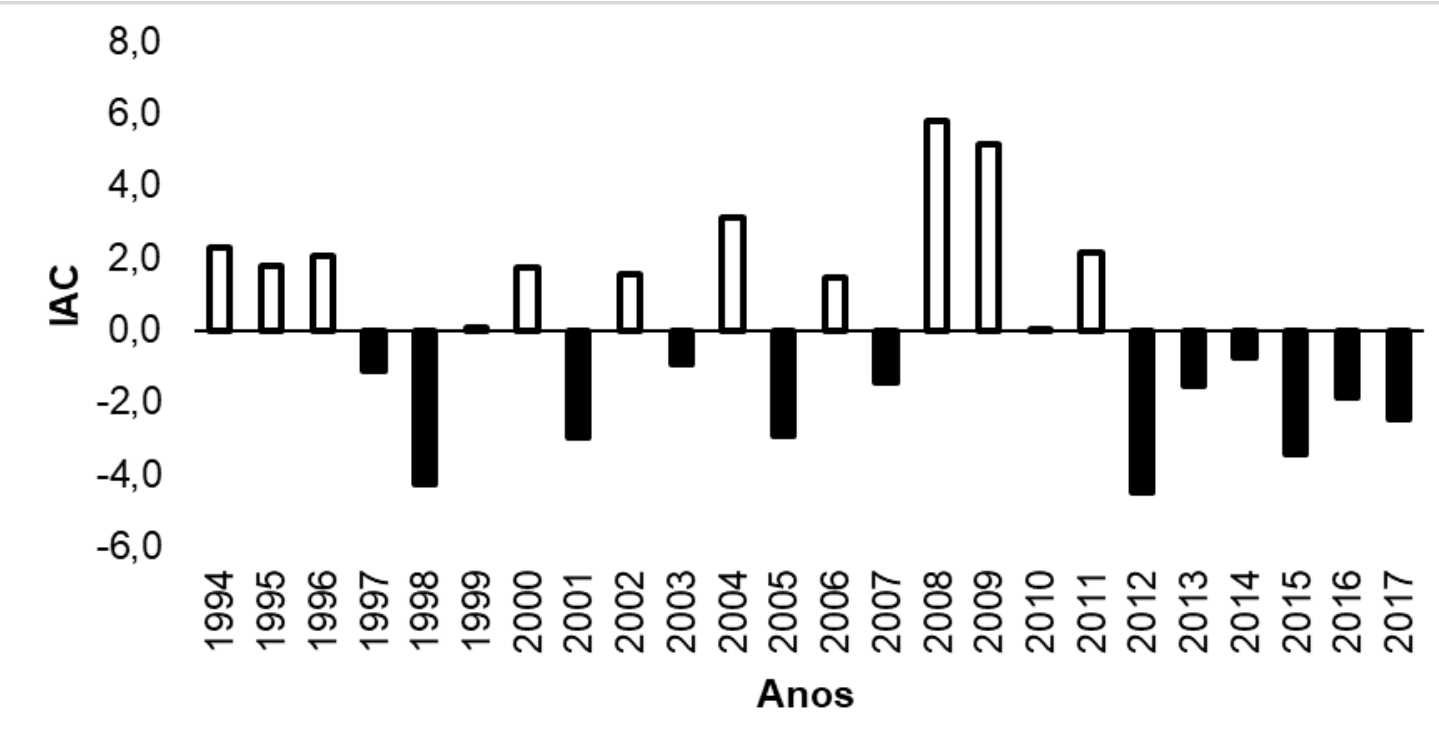

Fonte: Elaborada pelos autores. 
Os resultados observados sobre o IAC da série histórica da microrregião de Sousa estão associados à crise hídrica em determinadas áreas, ocasionando secas e, em consequência, prejudicando a agricultura, devido à ausência de chuva, e a criação de animais. Segundo Wilhite (2003), todas as secas são determinadas pela ausência da precipitação, o que resulta na falta de água para a sobrevivência dos seres vivos ou para o desenvolvimento de atividades que necessitam desse bem natural.

Já os períodos úmidos, em determinados ambientes, podem carrear problemas, como na agricultura e enchentes nas cidades por falta de infraestrutura, corroborando com Souza e Azevedo (2012) que afirmam serem os fenômenos provenientes da variabilidade climática um determinante para problemáticas distintas, a exemplo de secas e chuvas intensas, que impactam no bem-estar da população e no meio ambiente.

Destaca-se ainda que, em séries grandes ou pequenas da precipitação, o importante é o entendimento da alternância de períodos chuvosos e secos, já que deste modo se notará um equilíbrio ecológico entre o homem e o meio natural. Portanto, durante essa série histórica, verificou-se uma estabilidade do IAC, com variações significativas entre anos secos e chuvosos.

Para melhor entender o comportamento deste índice, analisou-se o seu desempenho intra-anualmente, entre os anos considerados extremos, dois anos secos e dois chuvosos, valendo ser ressaltada a sua variação dentro da estação seca e chuvosa dos anos analisados.

Figura 10. Índice de Anomalia de Chuva (IAC) dos anos úmidos da Microrregião de Sousa-PB

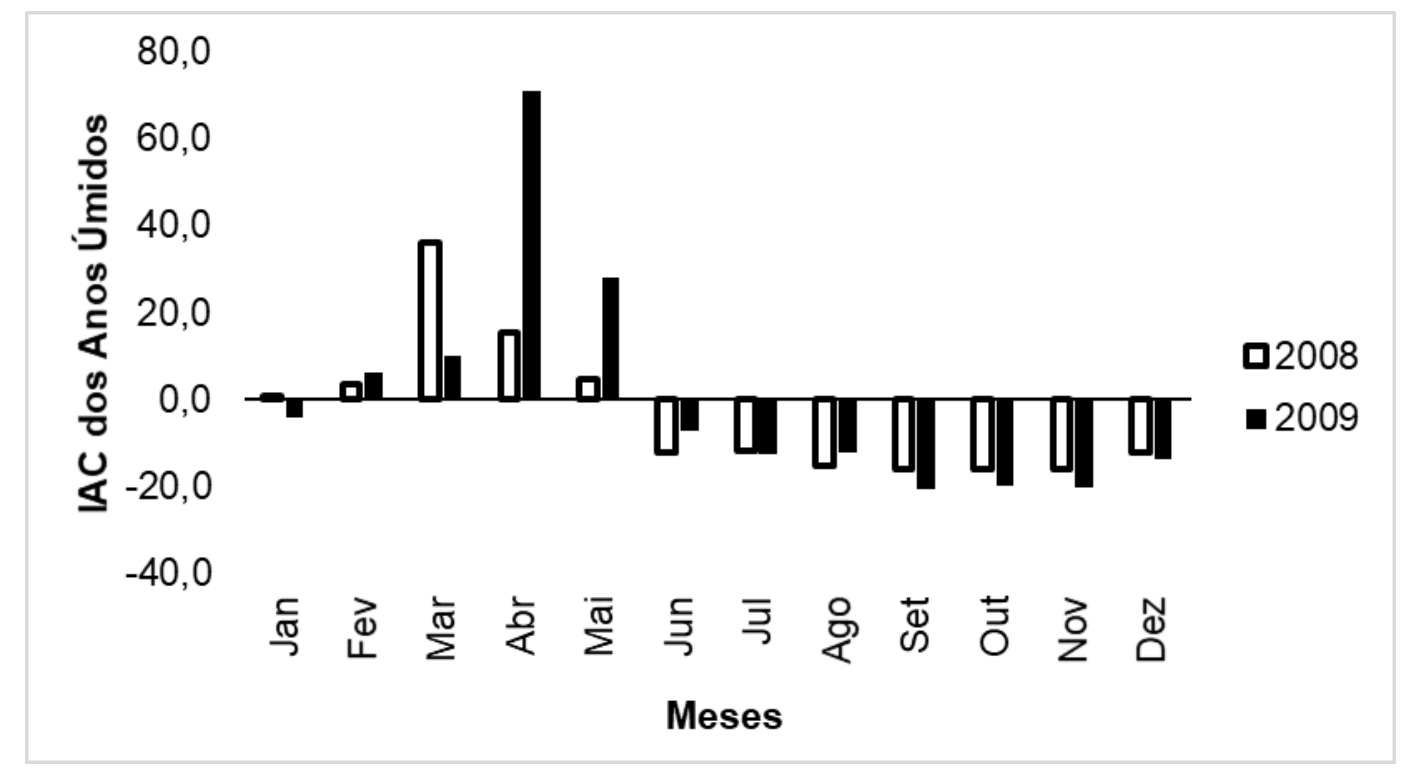

Fonte: Elaborada pelos autores.

Para os anos úmidos de 2008 e 2009 (Figura 10), considerados extremamente úmidos, apenas o mês de janeiro de 2009 não apresentou seu valor positivo de precipitação, obtendo assim o IAC negativo, ou seja, foi um mês dentro da estação chuvosa com poucas chuvas. Já na estação seca, que vai de junho a dezembro, todos os meses apresentaram valores dentro da sua normalidade. Deste modo, nota-se que apesar de o ano de 2009 ser extremamente úmido, o mês de janeiro obteve uma anomalia significativa.

Nos anos representados como secos, de
1998 e 2012, cujo IAC se mostrou negativo (Figura 11), observou-se que, dentro do período chuvoso, que vai de janeiro a maio (Figura 3), apenas o mês de maio desses anos não seguiu a variabilidade normal do seu período, ou seja, obteve o IAC negativo, corroborando com os resultados de Silva et al. (2009) que afirmam que o IAC, em anos secos, tende a ser mais negativo até mesmo no período chuvoso. Já no período seco, que vai de junho a dezembro, todos os meses seguiram sua normalidade não apresentando nenhuma anomalia. 
Figura 11. Índice de Anomalia de Chuva (IAC) dos anos secos da Microrregião de Sousa-PB

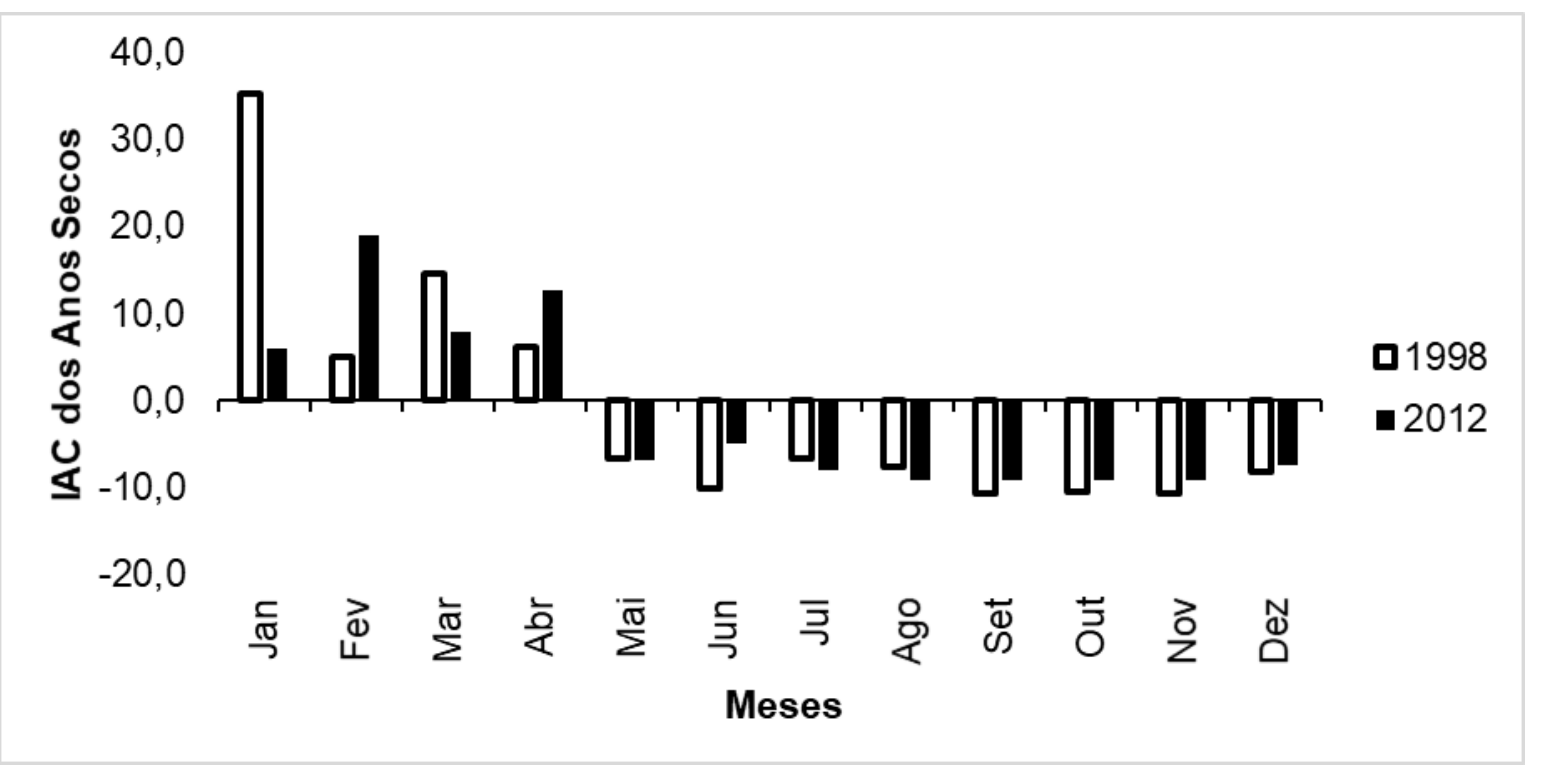

Fonte: Elaborada pelos autores.

\section{CONCLUSÕES}

De acordo com o presente trabalho, a microrregião de Sousa apresenta dois períodos distintos. O período chuvoso acontece de janeiro a maio, no qual o mês de março é o mais representativo em níveis de precipitação. Em compensação, o período seco ocorre de junho a dezembro, sendo setembro o mês destacado como o mais seco.

A distribuição espacial da precipitação da microrregião possui áreas bem distintas, em que a maior concentração de precipitação se localiza na parte sudoeste. Em contrapartida, a região noroeste e um ponto na parte central apresentaram valores baixos de precipitação. Já em relação à espacialização da precipitação mensal, evidenciou-se intensa e abrangente nos meses da estação chuvosa, a exemplo de março e abril, e diminuição significativa no período seco, em toda área estudada, nos meses de setembro e outubro.

A relação da espacialização da precipitação, proveniente da chuva orográfica, em comparação com a análise do relevo demonstrou que, nessa microrregião, alguns pontos apresentam influência direta do relevo, como evidenciado na parte noroeste o ponto mais seco; em contrapartida, a localidade mais chuvosa não sofre com a interferência do mesmo.

Conclui-se, ainda que o Índice de Anomalia de Chuva é uma ferramenta de importância significativa em todas as áreas ambientais, revelando-se como uma metodologia formidável para monitorar os períodos extremos (úmidos e secos) e para verificar o comportamento de uma determinada região. Deste modo, por meio do IAC foi possível comprovar que, na série histórica estudada, a microrregião de Sousa demonstra uma alternância entre anos secos e úmidos, constituindo $\mathrm{o}$ entendimento do equilíbrio ecológico de interação do homem com a natureza.

Esse trabalho traz uma relevante contribuição na área ambiental, pois seus resultados podem colaborar para 0 desenvolvimento da microrregião, uma vez que permite melhor caracterizar as condições de precipitação na área em estudo.

\section{AGRADECIMENTOS}

Os autores agradecem a AESA (Agência Executiva de Águas do Estado da Paraíba) pela parceria e disponibilidade dos dados para a realização da pesquisa. A CAPES (Coordenação de Aperfeiçoamento de Pessoal de Nível Superior) pela concessão da bolsa ao primeiro autor.

\section{REFERÊNCIAS BIBLIOGRÁFICAS}

ARAÚJO, L. E.; MORAES NETO, J. M. DE; SOUSA, F. DE A. S. Classificação da precipitação 
e da quadra chuvosa da Bacia do Rio Paraíba utilizando índice de anomalia de chuva (IAC). Revista Ambi-Água, v. 4, p. 93-110, 2009. doi:10.4136/ambi-agua.105

BARBOSA, M. R. C. Microrregião de Sousa-PB: um estudo sobre as condições de geração de emprego e renda. 2017. 84p. Monografia (Graduação em Ciências Econômicas) Universidade Federal da Paraíba, João Pessoa. 2017.

COSTA, J. A.; DA SILVA, D. F. Distribuição espaço-temporal do índice de anomalia de chuva para o estado do Ceará. Revista Brasileira de Geografia Física, v. 10, n. 4, p. 1002-1013, 2017. https://doi.org/10.26848/rbgf.v10.4.p1002-1013

DA SILVA, D.F. Análise de aspectos climatológicos, ambientais, agro-econômicos e de se seus efeitos sobre a Bacia hidrográfica do rio Mundaú (AL e PE). 2009. 174p. Tese (Doutorado em Recursos Naturais) Universidade Federal de Campina Grande, Campina Grande, 2009. Disponível:

http://dspace.sti.ufcg.edu.br:8080/jspui/handle/riuf $\mathrm{cg} / 3666$

DO SANTOS, E. P.; CORREIA, M. F.; ARAGÃO, M. R. S.; SILVA, F. D. S. Eventos extremos de chuva e alterações no regime hidrológico da Bacia Hidrográfica do Rio São Francisco: Uma aplicação do índice RAI (Rainfall Anomaly Index). Engenharia Ambiental, v. 8, p. 315-330, 2011. https://doi.org/10.1590/0102-778620130051

EMPRESA BRASILEIRA DE PESQUISA AGROPECUÁRIA - EMBRAPA. Serviço Nacional de Levantamento e Conservação de Solos (Rio de Janeiro, RJ). Súmula da 10. Reunião Técnica de Levantamento de Solos. Rio de Janeiro: 1979. 83p.

FERREIRA, P.S.; SOUZA, W. M.; SILVA, J. F. Variabilidade espaço-temporal das tendências de precipitação na mesorregião sul cearense e sua relação com as anomalias de TSM. Revista Brasileira de Meteorologia, v. 33, n. 1, p. 141152, 2018. ISSN 1982-4351. https://doi.org/10.1590/0102-7786331006.

FRANCISCO, P. R. M. Classificação e mapeamento de mecanização das terras do estado da Paraíba utilizando sistema de informações geográficas. Areia: UFPB/CCA, 2010. $107 \mathrm{f}$.
; MEDEIROS, R.M; SANTOS, D;

MATOS, R. M. Classificação climática de Köppen e Thornthwaite para o Estado da Paraíba.

Revista Brasileira de Geografia Física, v. 8, n. 4, p. 1006-1016, 2015.

https://doi.org/10.26848/rbgf.v8.4.

FREITAS, M. A. S. Um sistema de suporte à decisão para o monitoramento de secas meteorológicas em regiões semi-áridas. Revista Tecnologia, v.19, p. 84-95, 2005. https://doi.org/10.5020/23180730.1998.1175

IBGE - Instituto Brasileiro de Geografia e Estatística. Contagem da população 2017. Brasília: IBGE, 2017. s.p.

MACEDO, M. J. H.; GUEDES, R. V. S.; SOUSA, F. A. S.; DANTAS, F. R. C. Análise do índice padronizado de precipitação para o estado da Paraíba, Brasil. Revista Ambiente \& Água, v. 5, n. 1, p. 204-214, 2010. doi: 10.4136/ambiagua.130

NASCIMENTO, M. B.; BANDEIRA, M. M.; ARAÚJO, L. E. Variabilidade climática da precipitação do município de Areia/Paraíba, Brasil. Gaia Scientia, v. 13, n. 3, p. 24-37, 2019. https://doi.org/10.22478/ufpb.1981-

1268.2019v13n3.41925

NIKOLOVA, N. Regional climate change:

Precipitation variability in mountainous part of Bulgaria. Instituto Geográfico “jovancvijic” SASA.

Coleção de Papeis, p. 79-86, 2007.

https://doi.org/10.2298/IJGI0757079N

ROOY, M. P. van. A rainfall anomaly index independent of time and space. Notos, v. 14, p. 43-48, 1965.

SARMENTO, M. I. A.; NÓBREGA, E. P.; OLIVEIRA, P. R. R.; JUNIOR, E. B. P. Captação e aproveitamento de água da chuva em residências rurais no Município de Nazarezinho - Paraíba.

Revista de Agroec. no Semiárido, Sousa, v. 1, n. 1, p. 24-33, 2017. http://dx.doi.org/10.35512/ras.v1i1.1636

SILVA, D. F.; SOUSA F. A. S.; KAYANO M. T.; GALVÍNCIO J. D. Influência da variabilidade climática global e de suas escalas temporais sobre a precipitação no Alto Mundaú (PE).

Revista Brasileira de Geografia Física, v. 2, p. 64-82, 2009. https://doi.org/10.5935/1984$\underline{2295.20090012}$ 
SILVA V. P. R.; PEREIRA E.R. R.; ALMEIDA R. S. R. Estudo da variabilidade anual e intra-anual da precipitação na região Nordeste do Brasil.

Revista Brasileira de Meteorologia, v. 27, n. 2, p. 163-172, 2012. https://doi.org/10.1590/S010277862012000200005

SOUZA, W. M., AZEVEDO, P. V. Índices de detecção de mudanças climáticas derivados da precipitação pluviométrica e das temperaturas em Recife-PE. Revista Brasileira de Geografia Física, n. 1, p. 143-159, 2012.

https://doi.org/10.26848/rbgf.v5.1.p143-159

WILHITE, D. A. Drought. In: HOLTON, J. A.; PYLE, C.; CURRY, J.A. (Ed.). Encyclopedia of atmospheric science. New York: Elsevier, 2003. p. 650-658. 